\section{Existence and Significance of a Physiological Anticoagulating System}

When moderate doses of tissue thromboplastin are injected into the jugular vein of rats the circulating blood loses its clotting properties, with the result that no intravascular thrombi are, as a rule, produced. This effect of thromboplastin depends upon its capacity for inducing the formation of thrombin in blood from the plasma prothrombin. In most cases intravenous administration of moderate doses of thrombin to healthy animals does not cause thrombosis, for the clotting mechanism becomes disordered almost immediately after the injections. At the same time the thromboplastic activity of blood shows a sharp decrease, while fibrinogen capable of reacting with thrombin disappears and heparin-like substances appear in the blood. This protective reaction, maintaining the blood in a fluid state in the vascular bed when thrombin arises in it, is brought about by the physiological anticoagulating system. Experiments have shown that in narcotic sleep resulting from inhalation of sulphuric ether, as well as from anæsthesia produced by an intramuscular injection of novocaine on both sides of the spinal column, this anticoagulating system ceases to function. It is this effect that accounts for the fact that coagulation of circulating blood and death from thrombosis have been found to occur in anæsthetized test animals (as opposed to controls in a normal physiological condition) after an intravenous administration of certain doses of thrombin (Table 1).

It thus appears possible that there may exist certain receptors in the blood vessels which react to the presence of thrombin and actuate the neuro-humoral mechanism, preventing coagulation of the blood circulating in the vessels. There is no doubt that pathological changes in the vessel walls as well as impairment of circulation may lead to the formation of thrombin in the vascular bed. Whereas with an anticoagulating system functioning normally, the coagulation of the circulating blood is to a certain extent avoided, in any disturbance of that system the appearance of thrombin in the circulating blood, whatever its cause may be, can give rise to the formation of clots.

It is probable that the anticoagulating system partly loses its function as a result of changes in the body with age and of toxic effects occurring in case of some infectious diseases, as well as in narcosis or anæsthesia (post-operative thrombosis). The latter fact is proved experimentally. It is possible that in the normal physiology of blood a restricted formation of thrombin in the vascular bed is constantly taking place, but the blood does not clot owing to the action of the physiological anticoagulating system.

In cases of disturbance of the anticoagulating system, even with decreased prothrombin content in the blood and its slower conversion to thrombin, the possibility of the formation of thrombin still remains, a fact which does not exclude the conversion of fibrinogen to fibrin in the vascular bed.

On the basis of this hypothesis, the problem of thromboses should be approached not from the point of view of an excess of coagulating components in the circulating blood or the pathology of the vessel wall but through an analysis of the physiological state of the anticoagulating system present outside the vascular bed.

\section{B. A. KUDRJASHOV \\ P. D. ULYTINA}

Faculty of Biology and Soil Science, Moscow State University.

\section{Carbohydrate Metabolism of Cock Spermatozoa}

Glycolysis in spermatozoa of mammalian species has been much studied. These investigations, extensively reviewed by Mann $^{1}$, have demonstrated that mammalian spermatozoa utilize fructose, glucose and mannose; anaerobically, they degrade these sugars to lactic acid, deriving from this process the energy necessary for motility.

Winberg ${ }^{2}$ demonstrated that cock spermatozoa produce lactic acid by aerobic glycolysis of glucose, fructose or mannose, and that these sugars (and also maltose to a slight extent) support their respiration, but to my knowledge glyeolysis in avian spermatozoa has not been further studied systematically. This communication reports the results of an investigation on the carbohydrate metabolism of spermatozoa of the domestic cock (Gallus domesticus).

Semen collected from Rhode Island Red cocks by the abdominal massage method of Burrows and Quinn $^{3}$ was diluted, within $20 \mathrm{~min}$. of collection, with the pre-warmed appropriate medium, and then, after removing an aliquot for initial analysis, was incubated in a water-bath at $40^{\circ} \mathrm{C}$. The incubation was carried out in two ways: (1) in stoppered, 775 -mm. test tubes containing 1-2 ml. of the mixture, which were left undisturbed in the bath, thus pro-

Table 1. INhibition of the Anticoagulating System undkr the INfloence of Ether or Novocalne AN fisthesia

\begin{tabular}{|c|c|c|c|c|c|}
\hline No. of animals & $\begin{array}{c}\text { Activity of } \\
\text { thrombin (sec.)* }\end{array}$ & $\begin{array}{c}\text { Dose of intravenous } \\
\text { thrombin (ml.) }\end{array}$ & Experimental conditions & $\begin{array}{c}\text { No. of animals } \\
\text { surviving }\end{array}$ & $\begin{array}{l}\text { No. of animals dead } \\
\text { from thrombosis }\end{array}$ \\
\hline 30 & 6 & 0.5 & Animals anæsthetized with ether after & 5 & 25 \\
\hline 30 & 6 & 0.5 & Control animals in normal physiological & 26 & 4 \\
\hline 30 & 6 & $1 \cdot 0$ & $\begin{array}{l}\text { Control animals anasthetized with ether } \\
\text { after } 15 \text { min. sleep. Thrombin fully inact- } \\
\text { ivated by heating for } 6 \text { min at } 57^{\circ} \mathrm{C} \text {. }\end{array}$ & 30 & 0 \\
\hline 30 & 6 & 0.5 & $\begin{array}{l}\text { Animals given intramuscular injections of } \\
\text { novocaine along spinal column }\end{array}$ & 11 & 19 \\
\hline 30 & 6 & 0.5 & $\begin{array}{l}\text { Control animals in normal physiological } \\
\text { state }\end{array}$ & 26 & 4 \\
\hline 30 & 6 & 0.5 & $\begin{array}{l}\text { Control animals given intramuseular in- } \\
\text { jections of novocainealong spinal column. } \\
\text { Thrombin fully inactivated by heating } \\
\text { for } 6 \mathrm{~min} \text {. at } 57^{\circ} \mathrm{C} \text {. }\end{array}$ & 27 & 3 \\
\hline
\end{tabular}

* Thrombin solution clotted an equal volume of oxalated blood in $6 \mathrm{sec}$. at $37^{\circ} \mathrm{C}$. 